\title{
ANALYSIS OF ENERGY EFFICIENCY ASPECTS IN ENERGY MAN- AGEMENT MODEL OF BUNSE IN MANUFACTURE CASE STUDY: MANUFACTURING MANAGERS OF MOBARAKEH STEEL COMPLEX,
}

\section{3}

\author{
Bahare Asadollahi Esfahani ${ }^{1}$, Mohammad Reza Dalvi Esfahan ${ }^{2}$ \\ ${ }^{1}$ Department of Management, Najafabad Branch, Islamic Azad University, Najafabad, Iran \\ ${ }^{2}$ Assistant Professor of Islamic Azad University of Dehaghan, Management Group, Esfahan, Iran
}

\begin{abstract}
Correct energy management and its efficiency have been emphasized in industrial and manufacturing firms' policy makings for different reasons. Different studies focus on available potentials of these firms in the field of their energy efficiency. From among them just the fewest numbers of manufacturing enterprises could exploit them. Therefore the researcher intends to study some aspects of energy management model of Bunse in manufacture. Also by finding the differences and gaps between theories and available circumstance of the industry, this study encourages the Mobarakeh Steel Complex to execute energy efficiency management correctly. The results of the statistical analysis show that although there is not significant gap between industry's requirements and scientific literatures, based on the comparison of the present case and ideal circumstance of managers' point of view and because of the complex approximately proper condition, this complex has differences with worlds and scientific ideal standards.
\end{abstract}

Keywords: Energy Management, Key Performance Indicator, Benchmarking, Control and monitoring, Conceptual Framework, Energy Efficient Measurement.

\section{INTRODUCTION}

Industrial sectors are considered as one of the largest sectors of improving energy efficiency. So an extended range of energy efficiency measures in this sector is particularly developed and used by industrial sectors throughout the world[1]; [2].Energy is the core of social improvement and economical wealth and it is considered as an important factor in industrial and commercial products[3]. It is important to assert that energy saving is not only include costs' depression or concerning about environment problems but it also has capability to create a comparative advantage for manufacturing firms[4] \& [5].

Developing the accomplished measures in the field of energy management depends on using energy and performance of energy efficiency in industrial sector and detecting the existent barriers of energy efficiency improvement which indicates that how much performed measures and planned policies are effective in energy efficiency management field [6]. Energy efficiency measurement is the base of energy consumption control in manufacture and decision makings and the changes of trend in energy efficiency improvement [7]. Energy efficiency could be developed by applying modern technologies, conceptual framework tools about energy, energy recovering in that process by the use of energy wastes in different processes [8]. Up to now most of the policies related to energy consumption are made because of the increased energy demands and decrease of GHGs production but it encounters with serious challenges because of unclear reasons [3].

After releasing the costs of energy conveyers and its effects (on actual cost of productive items on the one hand and organizations' costs to offer services, energy management issue are considered as the up to dated issue [9]. Energy intensive industries (such as chemical products, steel, cement, paper, etc) includes more than two third of the worlds' industrial energy consumption [10]. Steel industry controls energy consumption level in different parts of manufacturing. Saving energy resources in steel industry is a critical issue in competitiveness of this industrial sector and also to minimize environmental effects as GHGs emission. The appearance of steel is inevitable in the manufacturing process, transformation and saving energy because of its' lightness, resistance and 100 percent reversibility [11].The goal of the present study is to analyze the gap between energy management's measurements, control and improvement of the industries' requirements and scientific literatures in Mobarakeh Steel Complex according to Bunse. And it attempts to specify the real needs of energy 
management in industrial and manufacturing sectors in this field and the scientific and operational gap.

\section{REVIEW OF SCIENTIFIC LITERATURES OF ENERGY MANAGEMENT}

Energy management in manufacturing sector includes controlling, monitoring and improving activities along with energy efficiency. Energy efficiency performance is assessed by considering other industrial firms' activity simultaneously [12]. It can be defined as the process of optimizing energy consumption which is compound of different skills of architecting, engineering, managing and etc[13].

Energy efficiency is calculated as the ratio of output energy to input energy [12]. One of the energy efficiency's barriers is the weak and low energy management in different industries. It also develops by the increase of enterprises' size and energy intensity level [14]. Energy management involves4 dimensions in the present study as key performance indicators, benchmarking, control and monitoring, evaluating conceptual framework.

\subsection{Energy Efficiency Measurement}

\subsubsection{Key Performance Indicators}

The process of measuring energy consumption has capability to assess optimization potentials and support the portrait of measurement energy management field [12].Normally indicators involve the described ratios between used energy and necessary energy relations. In industrial sectors this involves activities as products' manufacturing trends by physical or economic indicators or KPIs [15]. Followings are the proposed indicators in the present study;

Energy intensity (EI): Is an economical indicator for general and comprehensive levels that is given by consuming each GJ unit of energy per time unit [16].

Specific energy consumption: Is physical indicator proper for each level that is given by consuming each GJ unit of energy by every ton of products [17].

Both energy consumption indicators can be measured differently such as demands for primary energy conveyers, purchased energy or producing GHGs [18].

\subsubsection{Benchmarking}

In fact modeling and comparing different systems based on opposing performance criteria and wide range of available assessment data is a complicated task [19]. Policy makers mostly use energy benchmarking indicators in national levels to assess and grade available politic options, though the benchmarking indicators do not exist in organizational and minor levels [20]. Among benchmarking indicators and tools in this field we can name energy performance indicator (EnPI) to compare energy consumption in different level of a factory and Energy Star Label for factories that gain EnPI 75 and above (the range of 1 to 100).

\subsection{Controlling and Improving Energy Efficiency}

\subsubsection{Monitoring and Control}

Monitoring and analyzing energy consumed by machinery, repairs and manufacturing process is the first step to raise energy efficiency. Monitoring energy efficiency helps an enterprise to reach to the saved energy.

Auditing the energy is an important tool of energy management that helps policy makers to detect and specify the opportunities of improving energy efficiency and make them aware of the results of the decisions made before [21]. Auditing energy and controlling, analyzing and monitoring energy consumption accompany with a technical report and it is better for this report to involve suggestions for improving energy efficiency and be in accompanying with costs and benefit analysis of this suggestion and also executive strategies for controlling and minimizing energy consumption [22].

Energy auditing includes fallowing steps;

1. Walk through audit of energy: The goal of this audit is to estimate the value and cost of each energy conveyer in an installation process or system. This audit is quick and is designed for determining the project's potential [22]

2. Short audit of energy: Short audit of energy are resulted from primary audits. This audit provides the accurate analysis of particular projects [22].

3. Full audit of energy: Is a type of audit which includes long term and precise control of all equipments, processes and energy intensive machinery and calculates and extracts the lost energy, savings and costs comprehensively [22].

\subsubsection{Conceptual Frameworks}

The lack of proper concepts to evaluate energy efficiency put managers in trouble to measure, control and improve it. One of the concepts given in the present study is Environmental Management Accounting (EMA) that supports decision makers in the field of energy by tracking environmental costs and energy aspects [23] and also Balance Score Card (BSC) that converts enterprises' major strategic goals in energy sector to measurable indicators and creates a balanced distribution among critical areas of enterprise.

The present study is designed based on energy management model of Bunse in manufacture industry and the study's aspects are driven based on this model. According to the energy management model in manufacture (fig 1) energy efficiency measurement is the base of energy consumption in 
manufacture and are considered as feedback input data of measurement, control and monitoring in this model.

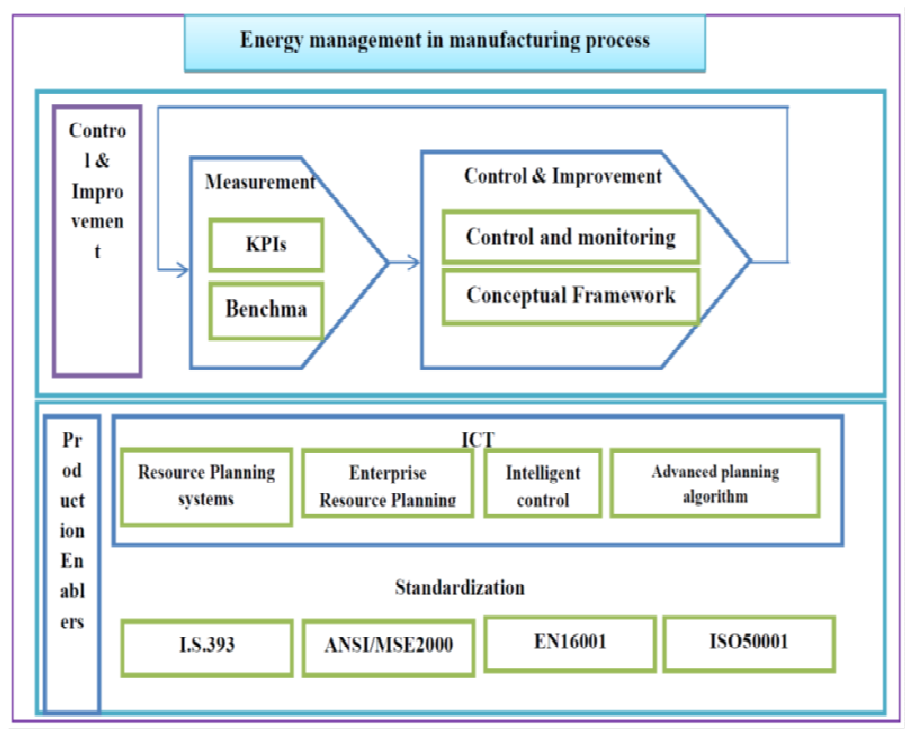

Fig -1: Model of energy management in manufacture

Measurement includes key performance indicators and modeling and control of improvement involves controlling, and monitoring conceptual frameworks of assessment. Moreover, ICT and Standardization have effective roles in this field and improvement operationally [12].

\section{RESEARCH HYPOTHESES}

Based on the given model and observed variables, the fallowing hypotheses are proposed;

1. There is significant gap between key performance indicators of industry requirements and scientific literature based on energy management.

2. There is significant gap between benchmarking of industry requirements and scientific literature based on energy management.

3. There is significant gap between monitoring and control of industry requirements and scientific literature based on energy management.

4. There is significant gap between conceptual framework of industry requirements and scientific literature based on energy management.

\section{METHODOLOGY}

Steel Complex samples are selected by census sampling methods. To detect the research variables' indicators, first some explanatory studies were done then all indicators were categorized and necessary measures were taken to prepare questionnaire. The reliability of the questionnaire was tested by factor analysis and the validity of 30distributed questionnaires were approved by Cronbach Alfa. Finally the final version of questionnaire distributed among manufacturing managers and they considered as the base of this analysis. After the text edit has been completed, the paper is ready for the template. Duplicate the template file by using the Save As command, and use the naming convention prescribed by your conference for the name of your paper. In this newly created file, highlight all of the contents and import your prepared text file. You are now ready to style your paper; use the scroll down window on the left of the MS Word Format-ting toolbar.

\section{FINDINGS}

Fallowing graph shows the mean of energy management variables and current case and ideal circumstance. According to this graph monitoring and control variable has the highest mean value that shows the least available gap among other variables.

Fig 2: The graph of the current case and ideal circumstance of energy management aspects

According to Table 1the observed t value is significant which approves the hypothesis. So it indicates that key performance indicator in Mobarakeh complex has a proper condition and there is not significant gap between industry's requirements and scientific literatures.

Based on table 1 the observed $t$ value is significant and the second hypothesis is approved. So there is no significant gap between benchmarking of industry's requirements and scientific literatures of energy management.

Also based on table 1 the observed t value is significant and the third hypothesis is approved. So there is no significant gap between monitoring and control of industry's requirements and scientific literatures of energy management.

And finally according to table 1 the observed $t$ value is significant and the forth hypothesis is approved. So there is no significant gap between conceptual frameworks of industry's requirements and scientific literatures of energy management.

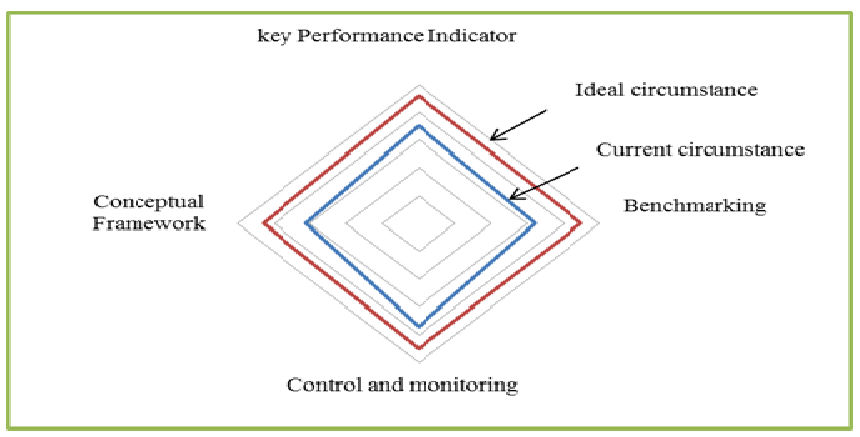

Fig 2: The graph of the current case and ideal circumstance of energy management aspects 


\section{RESULTS AND DISCUSSIONS}

The results show that there is no significant gap between the variables of industry's requirements and scientific literatures of energy management. But because of the least difference of some variables as benchmarking and conceptual frameworks of mean value, 3 , and also because of the difference between the present case and ideal circumstance from each other, it can be said that there is significant gap between current gaps and international standards.

First hypothesis: There is significant gap between key performance indicators of industry requirements and scientific literatures based on energy management.

Table -1: One sample t test of hypotheses

\begin{tabular}{|l|l|l|l|l|}
\hline hypothesis performance & Mean & T & d.f & $\mathrm{p}$ \\
\hline $\begin{array}{l}\text { key } \\
\text { indicators }\end{array}$ & 3.5 & 4.5 & 62 & 0.000 \\
\hline Benchmarking & 3.2 & 2.9 & 62 & 0.004 \\
\hline Monitoring and Control & 3.7 & 5.7 & 62 & 0.000 \\
\hline Conceptual framework & 3.1 & 1.5 & 62 & 0.12 \\
\hline
\end{tabular}

As indicated above one sample t test was applied on key performance indicators of scientific literatures and industry's requirements and the results of the test is indicated in Table land shows that key performance indicators of Mobarakeh steel complex is at nearly good condition and there is no significant gap between industry's requirements and scientific literatures. The resulted mean value is 3.5 and it shows that the first hypothesis is rejected.

Second hypothesis: There is significant gap between benchmarking of industry requirements and scientific literatures based on energy management.

As indicated above one sample $t$ test was applied on benchmarking of scientific literatures and industry's requirements and the results of the test is indicated in Table land shows that benchmarking of Mobarakeh Steel Complex is not good and there is no significant gap between industry's requirements and scientific literatures. The resulted mean value is 3.2 and it shows that the second hypothesis is rejected.

Third hypothesis: There is significant gap between monitoring and control of industry requirements and scientific literatures based on energy management.

One sample $\mathrm{t}$ test was applied on monitoring and control variable of scientific literatures and industry's requirements and the results of the test is indicated in Table 1and shows that monitoring and control of Mobarakeh Steel Complex is nearly good and there is no significant gap between industry's requirements and scientific literatures. The resulted mean value is 3.7 and it shows that the third hypothesis is rejected.
Forth hypothesis: There is significant gap between conceptual framework of industry requirements and scientific literature based on energy management.

One sample $\mathrm{t}$ test was applied on conceptual frameworks variable of scientific literatures and industry's requirements and the results of the test is indicated in Table 1and shows that conceptual framework of Mobarakeh Steel Complex is not so good and there is no significant gap between industry's requirements and scientific literatures. The resulted mean value is 3.1 and it shows that the forth hypothesis is rejected.

\section{SUGGESTIONS AND STRATEGIES}

Possibly Mobarakeh Steel Complex be at higher level of energy management and efficiency in comparison with other related factories. However, based on the results it is not adopted with proposed theories in various sciences and according to the results of the questionnaire that is related to ideal circumstance from manufacture managers point of view and also based on the graph 4.5 Mobarakeh has not so good condition and this includes two reasons:

- Mobarakeh Steel Complex is different from international standards.

- $\quad$ Some of the theories (at least those included in industry sector) are not operational.

So the fallowing strategies are proposed based on the results of the study.

\subsection{Strategies for Removing Key Performance}

\section{Indicators of Scientific Literatures and Industry}

\section{Requirements}

1. Most of the key performance indicators of energy management are defined for national level while it is better to define these indicators quantitatively and for factory and its processes.

2. The available indicators can be removed by Carbon standardization.

3. Indicators can be defined and used based on the shortages of other dimensions of energy management.

4. Key Performance Indicators should be developed through measuring energy efficiency and Carbon emission.

5. As the efficiency level of this sector is low, so to execute a precise policymaking on this field it is better for energy and its efficiency to be measurable. Therefore it is a good idea to define key performance indicators quantitatively not qualitatively. 


\subsection{Strategies for Removing Benchmarking Gaps of}

\section{Scientific Literatures and Industry's Requirements}

1. The applied indicators in the present study are used for comparing and modeling energy for the total performance of the factory audit is better to define these scales in minor levels as machineries of the factory.

2. The scales of each industry is different from other industries.

3. Modeling and related criteria should control similar challenges in the firms and be available for other similar firms. 4. As modeling of energy efficiency input is suitable mostly for national level so it is better to define these inputs for other industrial sectors and other sectors.

\subsection{Strategies for Removing the Gap between}

Monitoring and Control of Scientific Literatures and

\section{Industry's Requirements}

1. Monitoring and control variable in theories includes energy audit, energy balance sheet, and the use of sensors and technology measurement, as the available energy balance sheet are designed for national major level, so it is better to remove energy balance sheet or to provide them for particular factory.

2. Application of sensors and measurement technologies are more operational because of the appearance of real data.

3. In this field it appears that the lack of tacit or damaged machinery is felt to improve energy efficiency.

4. It is important to provide an accurate profile of machinery and instruments and use them to control the factory's energy efficiency.

To sum up, it appears that based on the results, monitoring and control variable is at good condition and it appears that Mobarakeh Complex could remove all gaps to some extent.

\subsection{Strategies for Removing the Gap between}

\section{Conceptual Frameworks of Scientific Literatures and}

\section{Industry's Requirement:}

1. The conceptual frameworks in theories involve environmental management accounting tools, balanced score card and etc. However based on the results of the study it appears that these frameworks are not operational at least in steel industry. And it is better to create new concepts of managements to analyze the costs, profits and etc.

2. Frameworks as the multi criteria supporting tools of decision making could be used for optimizing energy [12].

3. As the conceptual frameworks for assessment are de-signed for controlling and managing energy in manufacture, so it is better to plan frameworks in this field.
4. It is a good idea to improve calculation tools of costs of energy and its resources to estimate the cost and offer it to customers.

\section{REFERENCES}

[1]. Tanaka, K., 2011. Assessment of energy efficiency performance measures in industry and their application for policy. Energy Policy 36, 2887_2902.

[2]. World Energy Council (WEC) (2008), Energy Efficiency Policies Around the World: Review and Evaluation, WEC, Lon-don, available www.worldenergy.org/publications/ assess-ment_of_energy_policy_and_practices/default.asp (ac-cessed 3 October 2011).

[3]. Dong, C., Huang, G.H., Cai , Y.P., Liu, Y.,2013. Robust planning of energy management systems with environmental and constraint-conservative considerations under multiple uncertainties. Energy Conversion and Management 65, 471486.

[4]. Bassi, A.M., Yudken, J.S. and Ruth, M. (2009), "Climate policy impacts on the competitiveness of energy-intensive manufacturing sectors", Energy Policy, Vol. 37 No. 8, pp. 3052-60.

[5]. Zhao, Y-H. (2011), “The study of effect of carbon tax on the international competitiveness of energy-intensive industries: an empirical analysis of OECD 21 countries, 19922008", Energy Procedia, Vol. 5, pp. 1291-302.

[6]. Ozolina ,L.,Rosa ,M.,2012. A review of energy efficiency policy and measures for industries in Latvia. Management of Environmental Quality: An International Journal Vol. 23 No. 5, pp. 517-526.

[7]. Bunse, K., Sachs, J., Vodicka, M., 2010. Evaluating energy efficiency improvements in manufacturing processes. In: Vallespir, B., Alix, T. (Eds.), Advances in Production Management Systems. New Challenges, New Approaches. Springer, Boston, pp.19-26.

[8]. Rahimifard, S., Seow, Y., Childs, T., 2010. Minimising embodied product energy to support energy efficient manufacturing. CIRP Annals _ Manufacturing Technology 59, 25_28.

[9]. Rohdin, P., Thollander, P., 2006. Barriers to and driving forces for energy efficiency in the non-energy intensive manufacturing industry in Sweden. Energy 31,1836-1844

[10]. Velazquez, D., Gonzalez Falcon ,R., Lombard , L., Marina Gallego ,L., Biscarri , F., 2013, Development of an energy man-agement system for a naphtha reforming plant:A data mining approach, Energy Conversion and Management $67,217-225$.

[11]. Khandadashpoor, M.2012.Comparing Manufacture Tech-niques of Steel by the execution of , Articles are related to Steel Technic Firm.

[12]. Bunse, K., Vodicka, M., 2011. Integrating energy efficiency performance in production management _ gap analysis between industrial needs and scientific literature. Journal of Cleaner Production 19, 667-679. 
[13]. Lee , Sh.K., Teng , M., Fan ,K. SH., Yang ,K.H. , Horng , R.S.,2011, Application of an energy management system in combination with FMCS to high energy consuming IT industries of Taiwan, Energy Conversion and Management 52 ,3060-3070.

[14]. Thollander, P., Ottosson, M., 2010. Energy management practices in Swedish.

[15]. Ang, B.W., 2006. Monitoring changes in economy-wide energy efficiency: from energy-GDP ratio to composite efficiency index. Energy Policy 34, 574-582.

[16]. Irrek, W., Thomas, S., 2006. The energy-efficiency gap what does it mean? Energy Policy 22, 804-810.

[17]. Boyd, G., Dutrow, E., Tunnessen, W., 2009. The evolution of the ENERGY STAR energy performance indicator for benchmarking industrial plant

[18]. Mukherjee, K., 2008. Energy use efficiency in U.S. manufacturing: a nonparametric analysis. Energy Economics 30, 76-96.

[19]. Braglia, M., Zanoni, S., Zavanella, L., 2003. Measuring and benchmarking productive systems performances using DEA: an industrial case. Production Planning \&Control 14, 542-554

[20]. Phylipsen, D., Blok, K., Worrell, E., de Beer, J., 2002. Benchmarking the energy efficiency of Dutch industry: an assessment of the expected effect on energy consumption and CO2 emissions Energy Policy 30, 663-679

[21]. Zilahy, G., 2004. Organisational factors determining the implementation of cleaner production measures in the corporate sector Journal of Cleaner Production 12,311-319

[22]. Scientific and Operational reference of energy management by execution of subsidies purposivism law, Tehran, Sharif University Publications.

[23]. Burritt, R.L., Saka, C., 2006. Environmental management accounting applications and eco-efficiency: case studies from Japan. Journal of Cleaner Production 14,12621275 . 